\title{
Trastornos fisiológicos de la papa - Grietas de Crecimiento'
}

\author{
L. Zotarelli, C. Hutchinson, S. Byrd, D. Gergela, y D. L. Rowland ${ }^{2}$
}

Las grietas de crecimiento son un trastorno fisiológigo externo no infeccioso del tubérculo de la papa en el que el tubérculo se agrieta durante el crecimiento. La bendidura se cura, pero deja una fisura en el tubérculo. Las grietas de crecimiento generalmente ocurren en el extremo apical o brote de la papa y se pueden extender longitudinalmente. Éstas varían en severidad desde una abrasión en la superficie a una división en el tubérculo, dependiendo de la etapa de crecimiento durante la cual el agrietamiento inicial haya ocurrido (Fig. 1).

A pesar de que el agrietamiento no suele predisponer al tubérculo a su pudrición, las grietas de crecimiento pueden impactar negativamente la calidad de éste. Las grietas de crecimiento hacen a los tubérculos poco atractivos para el mercado fresco.

Las grietas de crecimiento severo pueden impactar la calidad de las papas fritas y afectar el procesamiento (Fig. 2).

Las grietas de crecimiento se forman debido a las fluctuaciones en las condiciones ambientales, tales como la desigualdad de la humedad del suelo, la temperatura del aire y del suelo, la rapidez de la absorción del agua y el crecimiento del tubérculo (Hiller y Thornton 2008; Jefferies y MacKerron 1987). Las grietas de crecimiento aumentan

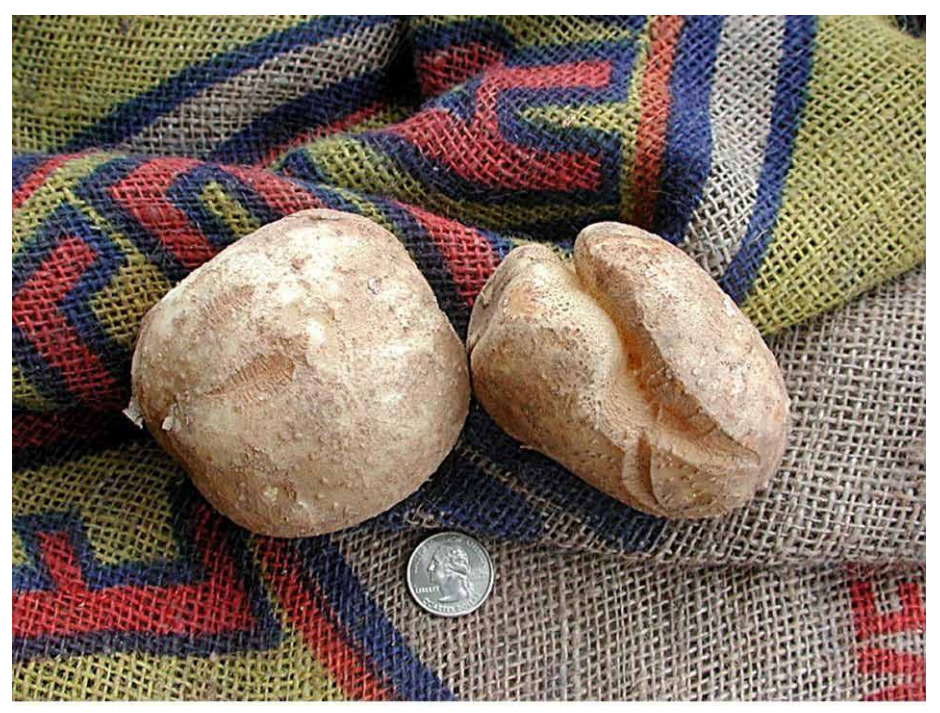

Figure 1. Grietas de crecimiento moderadas (izquierda) y severas (derecha) en 'Atlántic'. Créditos: C. Hutchinson

cuando condiciones de crecimiento relativamente pobres son rápidamente seguidas por buenas condiciones de crecimiento, tales como un estrés hídrico prolongado o altas temperaturas, seguidos por un exceso de lluvia o riego (Selman y col. 2008). La severidad de las grietas de crecimiento aumenta en las plantas que están ampliamente espaciadas o plantadas en densidades inusualmente bajas. Además, el agrietamiento se agrava si el fertilizante es aplicado desigualmente, especialmente cuando el nitrógeno

1. Este documento, HS1211, es uno de una serie de publicaciones del Horticultural Sciences, Servicio de Extensión Cooperativa de la Florida, Instituto de Alimentos y Ciencias Agrícolas, Universidad de la Florida. (UF/IFAS). Fecha de primera publicación: January 2013. Visite nuestro sitio web EDIS en $<$ http://edis.ifas.ufl.edu>. This is a translation of HS930, Potato Physiological Disorders - Growth Cracks.

2. L. Zotarelli, assistant professor, Horticultural Sciences Department; C. Hutchinson, former associate professor, Horticultural Sciences Department; S. Byrd, graduate student, Agronomy Department; D. Gergela, research coordinator, Florida Partnership for Water, Agriculture and Community Sustainability at Hastings; and D. L. Rowland, associate professor, Agronomy Department, Cooperative Extension Service, Institute of Food and Agricultural Sciences, University of Florida, Gainesville, FL 32611. 


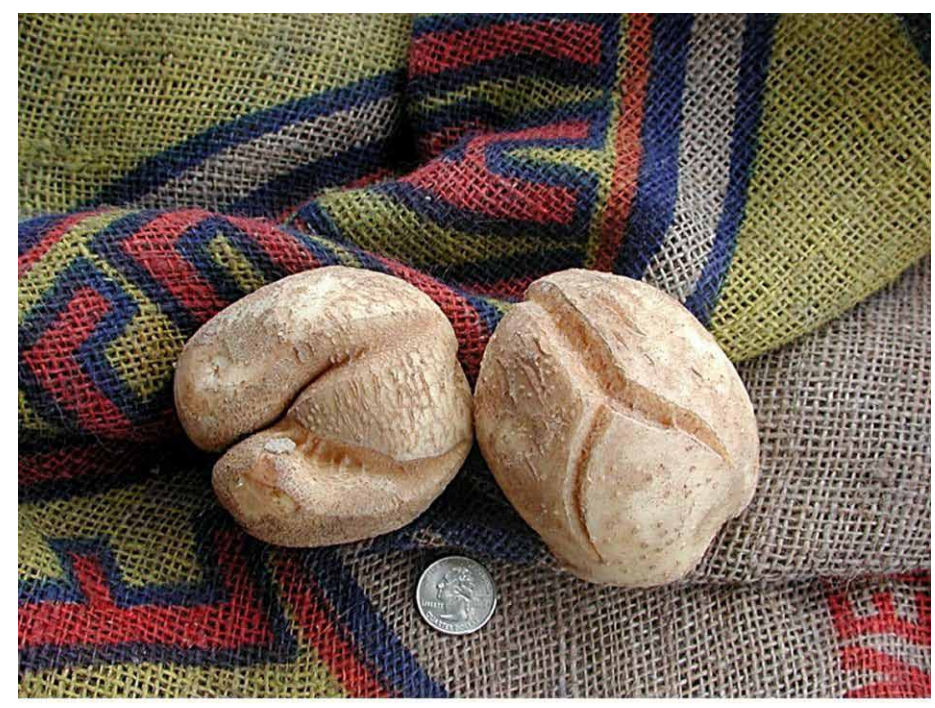

Figure 2. Ejemplos de grietas de crecimiento severas en 'Atlantic' que reducirían su comerciabilidad. Créditos: $C$. Hutchinson

es aplicado en exceso o cuando la aplicación de éste no es programada apropiadamente.

También existe una relación entre bajos niveles de boro en el suelo y el aumento de la intensidad de las grietas de crecimiento (Hiller, Koller, y Thornton 1985). Existen evidencias de que las plantas de papa infectadas con virus que exhiben síntomas de mosaico (coloración moteada en las hojas) tienen una incidencia elevada de grietas de crecimiento (Carnegie y McCreath 2010). Hay diferencias en la susceptibilidad de las variedades de papa a las grietas de crecimiento. 'Atlantic', la papa mayormente cultivada para el procesamiento de papas fritas en Florida, y 'Red Lasoda', una variedad común para el consumo fresco, son relativamente susceptibles al trastorno. Los ensayos de las variedades de papa en Florida han demostrado que la mayoría de las variedades estándar cultivadas en Florida (ej. 'La Chipper', 'Harley Blackwell', etc.), no son susceptibles en la mayoría de los años, pero el clima ha influenciado la incidencia en años calientes y húmedos (Fig. 3).

Para reducir la incidencia de grietas de crecimiento, mantenga una humedad en el suelo apropiada durante la temporada. Esto es especialmente importante durante la etapa de llenado, cuando las plantas están grandes y sus tubérculos están creciendo rápidamente. En Florida, esta etapa se produce al final de la temporada cuando las temperaturas del aire y del suelo aumentan rápidamente. Las plantas grandes y los tubérculos que se expanden requieren más agua para mantener un buen crecimiento. Otras recomendaciones para reducir la incidencia de las grietas de crecimiento incluyen el espaciar las plantas uniformemente, aplicar el riego de forma uniforme para mantener la humedad del suelo a un nivel consistente

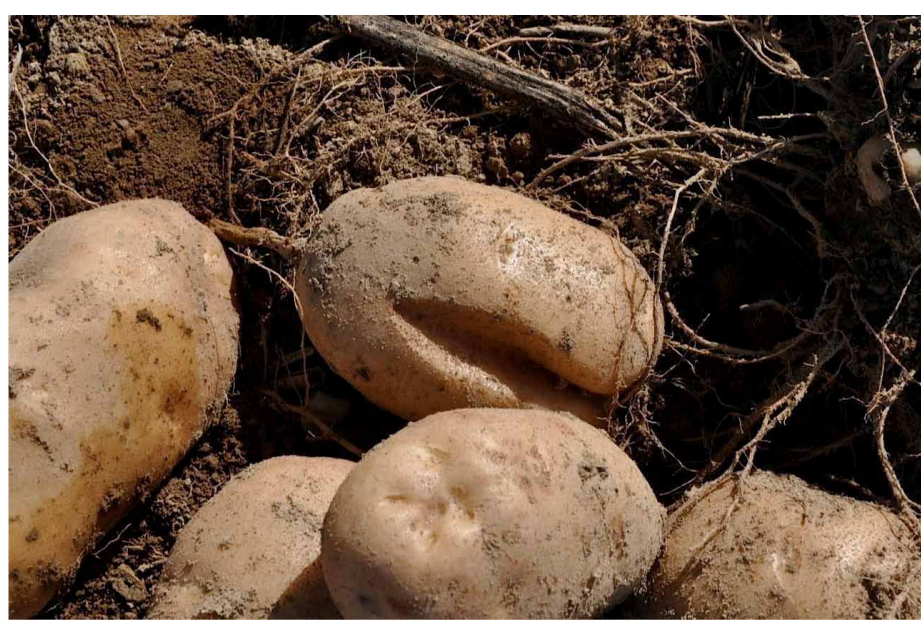

Figure 3. Ejemplo de grietas de crecimiento severas en una variedad de papas para hornear. Créditos: L. Zotarelli

y asegurar la aplicación precisa de fertilizante tanto en cantidad como localización.

El único recurso cuando la incidencia de grietas de crecimiento es alta, es la separación de los tubérculos con grietas de crecimiento severas antes de su envasado y/o transporte.

\section{Más Información}

Bohl, W. H., y S. B. Johnson, eds. 2010. "Commercial Potato Production in North America: The Potato Association of America Handbook." The Potato Association of America. http://potatoassociation.org/documents/A_Pro- ductionHandbook_Final_000.pdf.

Zotarelli, L., P. D. Roberts, P. J. Dittmar, S. E. Webb, S. A. Smith, B. M. Santos, y S. M. Olson. 2012. Potato Production in Florida. HS733. Gainesville: University of Florida Institute of Food and Agricultural Sciences. http://edis.ifas. ufl.edu/cv131.

\section{Referencias}

Carnegie, S. F., and M. McCreath. 2010. "Mosaic Virus Symptoms in Potato Crops and the Occurrence of Growth Cracking in Tubers." Potato Research 53(1): 17-24.

Hiller, L. K., D. C. Koller, and R. E. Thornton. 1985. "Physiological Disorders of Potatoes." In Potato Physiology, edited by P.H. Li, 389-455. New York: Academic Press.

Hiller, L.K., and R. E. Thornton. 2008. "Managing Physi- ological Disorders." In Potato Health Management: Plant Health Management Series, edited by D. A. Johnson, 235-245. St. Paul, MN: The American Phytopathological Society. 
Jefferies, R. A., and D. K. L. MacKerron. 1987. “Observa-

tions on the Incidence of Tuber Growth Cracking in

Relation to Weather Patterns." Potato Research 30(4):

613-623.

Selman, L., N. Andrews, A. Stone, and A. Mosley. 2008.

"What's Wrong with My Potato Tubers? Diagnosing Tuber Abnormalities in Western Oregon and Washington."

Oregon State University Extension Service and Western

Region Sustainable Agriculture Research and Education.

Accessed January 8, 2012. http://extension.oregonstate.edu/

catalog/pdf/em/em8948-e.pdf. 